\title{
Analysis on the Application of Ecological Water Conservancy Design Concept in Urban River Channel Planning and Design
}

\section{Gao Guifen}

Yunnan Technology and Business College, Yunnan, China

Keywords: ecological water conservancy project; river planning; measures and applications

\begin{abstract}
River planning is an important part of urban planning and construction. In order to realize the ecological development of urban construction and improve the quality of people's living environment, it is necessary to carry out ecological planning and construction of urban river construction. This paper starts with the problems existing in the development of river planning in China, based on the ecological water conservancy project to carry out planning and design of the river channel, and promote the sustainable development of urban construction in China.
\end{abstract}

\section{Introduction}

The construction of ecological water conservancy project is based on the construction of traditional water conservancy projects, and incorporates the concept of ecological development into the construction and planning of urban water conservancy projects, making the construction of ecological water conservancy projects a comprehensive, integrated and sustainable development concept. . Ecological water conservancy project is an important branch of water conservancy project construction. The ecological development concept incorporates the green development concept of ecological development concept, ecological culture concept and ecological development humanistic concept, which provides a new theoretical guidance for urban river construction in China.

\section{Principles for the construction of ecological water conservancy projects}

The construction of ecological water conservancy projects is an important part of modern water conservancy construction and an important theoretical concept for realizing green development in urban construction in China. The principles adhered to in the construction of ecological water conservancy projects are: protection-oriented, development- supplemented; adhering to human-centered construction; adapting to local conditions and diversifying development. The principles of adhering to the ecological water conservancy project in the construction and improvement of rivers in modern cities provide guiding theories for the construction of ecological rivers and promote the green development of urban construction.

\section{Current status of river planning development in China}

River construction is an important part of the construction of ecological water conservancy projects and an important part of urban construction. The following table shows the survey of river conditions in a certain city in China from 2011 to 2015. China's cities have gradually realized the comprehensive application of resources and the green development of urban construction, which has achieved certain results in the application of urban rivers, and the overall environmental problems of the cities have been significantly improved.

From the analysis of the data in the above table, it can be seen that in the past five years, the proportion of river construction in the city's overall construction and the ratio of overall urban construction optimization rate have changed greatly; the comprehensive application rate of river channels, the rate of innovation in river channel construction, and Residents' satisfaction with urban river construction is less variable. It can be seen that the current river construction in China's urban 
construction has achieved great results, but there are still some problems that require builders to conduct in-depth exploration.

Table 1: Survey data of river conditions in a certain city in China from 2011 to 2015

\begin{tabular}{ccccc}
\hline Year & $\begin{array}{c}\text { Proportion of river channel } \\
\text { construction in urban } \\
\text { construction /\% }\end{array}$ & $\begin{array}{c}\text { River channel } \\
\text { comprehensive } \\
\text { application rate } \\
\text { /\% }\end{array}$ & $\begin{array}{c}\text { River channel } \\
\text { construction } \\
\text { form innovation } \\
\text { rate /\% }\end{array}$ & $\begin{array}{c}\text { City overall } \\
\text { construction } \\
\text { optimization } \\
\text { rate /\% }\end{array}$ \\
\hline $\mathbf{2 0 1 1}$ & 39 & 33 & 20 & 36 \\
$\mathbf{2 0 1 2}$ & 40 & 37 & 23 & 45 \\
$\mathbf{2 0 1 3}$ & 44 & 45 & 23 & 55 \\
$\mathbf{2 0 1 4}$ & 46 & 47 & 26 & 65 \\
$\mathbf{2 0 1 5}$ & 48 & 50 & 29 & 70 \\
\hline
\end{tabular}

\section{Problems in river channel planning and design}

\subsection{River channel planning and design concept lacks innovation}

From the survey data analysis of Current River planning and construction in China, we can see that there are still many problems in the construction of urban rivers in China. First of all, the concept of urban river channel construction lacks innovation: On the one hand, the composition elements of urban river channel construction are still dominated by large-scale water conservancy construction. Each river channel construction will consume a lot of manpower and material resources, resulting in the viciousness of urban river channel construction after pollution control. Recycling, lack of comprehensive application of rivers, lack of innovation in design and application; on the other hand, the implementation of ecological river construction in some cities in China is relatively low, and the construction concept of construction is still "one-sided" The lack of public participation in the construction and application of rivers leads to low satisfaction of residents in urban construction planning. This decisive construction idea cannot find problems in the construction of urban rivers and hinder the development of urban ecologicalization.

\subsection{River channel planning is low overall}

From the overall perspective of urban development, the overall planning of urban construction is low, and most of the rivers are randomly constructed and lack scientific, which leads to the impact of river construction on the comprehensive management of the ecological environment in the region. For example: In a certain city in China, river construction is carried out. However, due to the lack of scientific planning, the rivers are divided into channels, resulting in a significant reduction in the amount of water in the main rivers, and the death of a large number of aquatic organisms such as fish, which seriously undermines the ecological balance. In addition, due to the lack of scientific investigation in the construction of some rivers, the water volume increased after the river channel was drained, the original river bed was damaged, the river sides were severely impacted, and the soil erosion around the river channel was serious, which affected the overall construction of the area.

\subsection{River channel planning and construction is more uniform}

At present, the main form of river construction in China is to set the location of the river in the urban layout, and then excavate the river channel, and then complete the modern river construction according to the design of the river along the river channel. In the process of artificially implementing river channel construction, it is mainly based on later development, and the utilization rate of natural river channel construction is low, which makes the urban river channel construction lack of innovation, and also makes China's urban construction form tend to be "integrated" mode, leading to urban construction and There is a serious disconnect between ecological and water conservancy projects. The construction of the river channel is single, which makes the comprehensive utilization rate of river channel construction low. On the one hand, the 
construction of river courses is too much integrated into the concept of human transformation, the application level to natural rivers is low, and the comprehensive application of natural resources is not realized. On the other hand, the application of river banks for river construction is low, so that the construction of river courses only plays a role in regulation. The function of water quantity and flood reduction has not fully utilized the role of rivers.

\section{River planning optimization measures based on ecological water conservancy projects}

\subsection{Update the river design planning concept}

Combined with the current problems in the development of river application in China and the principles adhered to in the construction of ecological water conservancy projects, new measures for ecological river construction are proposed. First, update the river design planning concept and fully apply the modern shared development concept to build urban rivers. In the concept of river construction, we adhere to the theory of shared development of openness, sharing, innovation and environmental protection, and apply natural rivers to respect nature and transform nature, protect in development, and develop in protection. In addition, give full play to the role of urban residents in the construction of rivers, and pay attention to the innovation of urban river construction design concepts.

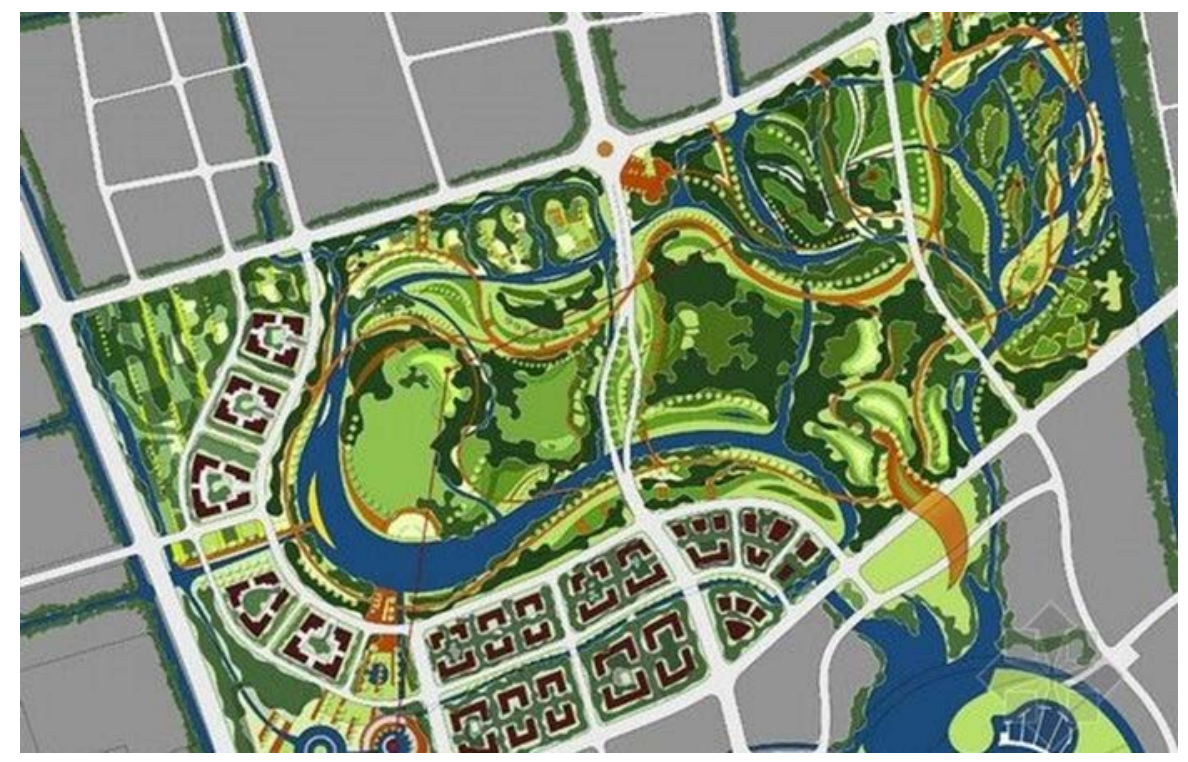

Figure 1: River construction plan for a certain city in China

For example: Figure 1 above is the design plan for urban river construction in a certain city in China. The local municipal construction management department fully strives for the opinions of the people, and makes secondary use of the original river channel in urban construction, and applies the gap design method on the basis of the original river channel. Urban rivers have realized the construction and application of ecological rivers.

\subsection{Focus on the integrity of the river design}

Due to the poor overall construction of rivers in some cities in China, the design and application of ecological water conservancy projects are applied to river design. Comprehensive planning of the river channels already established in urban construction, and maximizing the construction of the original river channels into a complete river management system. River construction adheres to the law of natural development, tries to avoid the conflict between urban river application and natural law, and focuses on the natural development law to realize ecological river construction. For example: In the process of urban river construction in a city, the city's internal water culture is considered comprehensively, and the balanced development of urban river construction and natural environmental protection is realized. 


\subsection{Improve the comprehensive utilization rate of rivers}

The main function of river construction is to do a good job of waterproofing and drainage of the city, making full use of natural water resources for water energy development and application, and it is also an important form of beautifying urban construction. From the main role of the river course, the comprehensive utilization of the river channel refers to the construction and utilization of the dam and river bed of the natural river channel, maximally exerting the role of the river channel, changing the uniform construction mode of the river channel construction, and transforming the river channel construction form; Said that the integration of urban construction concept, the construction of rivers as a city landscape construction

A part of. For example: When constructing urban river courses, flexible application of natural river channels, construction of green beaches on both sides of the river channel on the basis of the original river channels, and beautification of the river channel construction environment.

\section{Practical application of river planning based on ecological water conservancy project}

\subsection{Design Overview}

A city is located in the middle and lower reaches of the Yangtze River in China. There are 5 natural rivers, 5 established rivers and 2 abandoned rivers. The shape of the city is distributed.

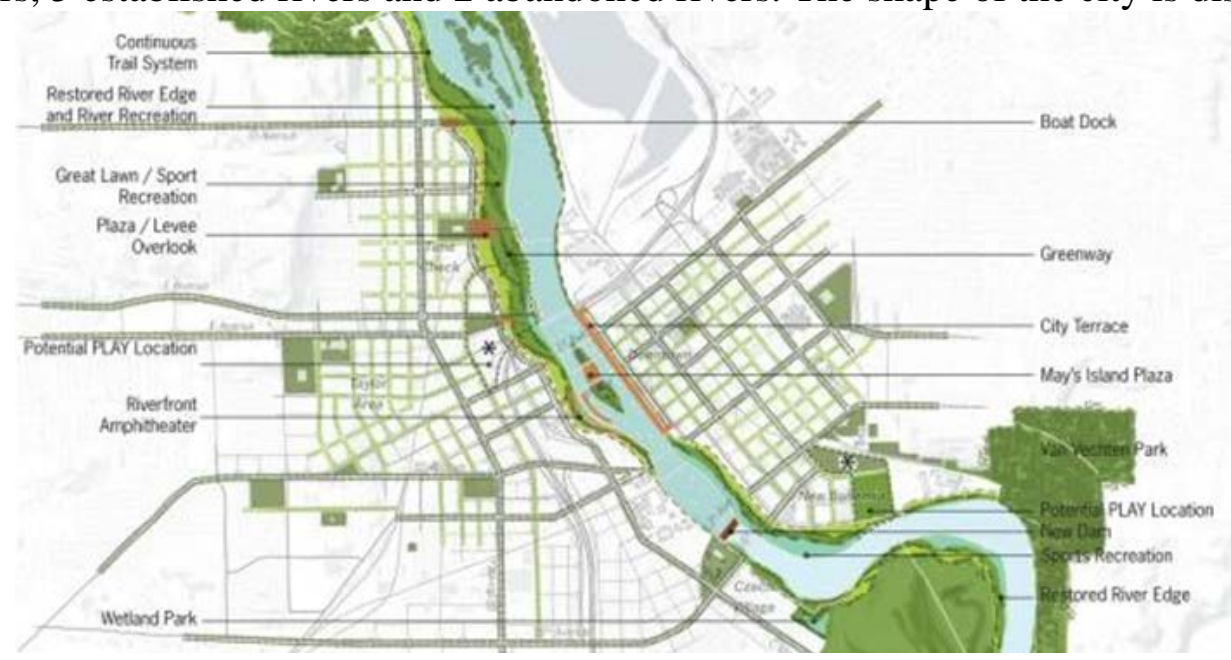

Figure 2: Riverbed application case in a city's river planning

In recent years, the application of riverbed in the city shown in Figure 2 above is relatively low, resulting in a low level of water resources application within the city, and a low level of application of the green concept of urban ecological environment construction. Secondly, the agricultural planting near the city is not affected by urban river construction. Due to the impact of science, floods often occur in agriculturally cultivated areas, resulting in lower agricultural returns.

\subsection{Design concept}

According to the distribution map of the city's rivers, the construction of the river channel in the city is designed by fully applying the concept of ecological water conservancy project construction. The design concept mainly includes: Comprehensive application of natural rivers in cities, so that existing rivers form a complete resource circulation system;

Re-treat the abandoned rivers in the city and rationally apply the abandoned resources; build new river systems according to the characteristics of urban construction, and realize the comprehensive application of urban rivers to realize the construction of urban ecological rivers.

\section{Conclusions}

River construction is an important part of urban construction. This paper is based on the preliminary study of river planning and design of ecological water conservancy projects, analyzes 
the development status of river construction in China, proposes problem-solving measures, and introduces cases for analysis.

To realize the ecological development of modern urban construction, it also provides an innovative development path for the application of natural resources in China and promotes the ecological development of socialist construction.

\section{References}

[1] Greco S E, Fremier A K, Larsen E W, et al. A tool for tracking floodplain age land surface patterns on a large meandering river with applications for ecological planning and restoration design [J]. Landscape \& Urban Planning, 2017, 81(4):354-373.

[2] Wang Z Y, Lee J H W, Melching C S. Mountain Rivers and Incised Channels[M]// River Dynamics and Integrated River Management. 2015.

[3] Zhang Y, Yang Z, Wei L I. Analyses of urban ecosystem based on information entropy[J]. Ecological Modelling, 2016, 197(1):1-12. 